\title{
Immune checkpoint inhibitors versus second line chemotherapy for patients with lung cancer refractory to first line chemotherapy
}

Citation for published version (APA):

Lefebvre, C., Martin, E., Hendriks, L. E. L., Veillon, R., Puisset, F., Mezquita, L., Ferrara, R., Sabatier, M., Filleron, T., Dingemans, A-M. C., Besse, B., Raherisson, C., \& Mazieres, J. (2020). Immune checkpoint inhibitors versus second line chemotherapy for patients with lung cancer refractory to first line chemotherapy. Respiratory medicine and research, 78, [100788].

https://doi.org/10.1016/j.resmer.2020.100788

Document status and date:

Published: 01/11/2020

DOI:

10.1016/j.resmer.2020.100788

Document Version:

Publisher's PDF, also known as Version of record

Document license:

Taverne

Please check the document version of this publication:

- A submitted manuscript is the version of the article upon submission and before peer-review. There can be important differences between the submitted version and the official published version of record.

People interested in the research are advised to contact the author for the final version of the publication, or visit the DOI to the publisher's website.

- The final author version and the galley proof are versions of the publication after peer review.

- The final published version features the final layout of the paper including the volume, issue and page numbers.

Link to publication

\footnotetext{
General rights rights.

- You may freely distribute the URL identifying the publication in the public portal. please follow below link for the End User Agreement:

www.umlib.nl/taverne-license

Take down policy

If you believe that this document breaches copyright please contact us at:

repository@maastrichtuniversity.nl

providing details and we will investigate your claim.
}

Copyright and moral rights for the publications made accessible in the public portal are retained by the authors and/or other copyright owners and it is a condition of accessing publications that users recognise and abide by the legal requirements associated with these

- Users may download and print one copy of any publication from the public portal for the purpose of private study or research.

- You may not further distribute the material or use it for any profit-making activity or commercial gain

If the publication is distributed under the terms of Article $25 \mathrm{fa}$ of the Dutch Copyright Act, indicated by the "Taverne" license above, 
Original article

\title{
Immune checkpoint inhibitors versus second line chemotherapy for patients with lung cancer refractory to first line chemotherapy
}

\author{
C. Lefebvre $^{\mathrm{a}}$, E. Martin ${ }^{\mathrm{b}}$, L.E.L. Hendriks ${ }^{\mathrm{c}}$, R. Veillon ${ }^{\mathrm{a}}$, F. Puisset ${ }^{\mathrm{f}}$, L. Mezquita ${ }^{\mathrm{d}}$, R. Ferrara ${ }^{\mathrm{d}}$, \\ M. Sabatier ${ }^{f}$, T. Filleron ${ }^{b}$, A.-M.C. Dingemans ${ }^{c}$, B. Besse ${ }^{d}$, C. Raherisson ${ }^{a}$, J. Mazières ${ }^{e, *}$ \\ a Department of Pneumology, University Hospital of Bordeaux, 33604 Pessac, France \\ b Biostatistics Unit, Institut Claudius Regaud, IUCT-O, Toulouse, France \\ ' Department of Pulmonology, GROW-School for Oncology and Developmental Biology, Maastricht University Medical Centre, Maastricht, Netherlands \\ d Institut d'Oncologie Thoracique, Institut Gustave Roussy, Villejuif, France \\ e Pulmonology Department, Toulouse University Hospital, Université Paul Sabatier, Toulouse, France \\ ${ }^{\mathrm{f}}$ Pharmacy department IUCT (Institut Universitaire du Cancer) Oncopole, Institut Claudius-Regaud, Toulouse, France
}

\section{A R T I C L E I N F O}

\section{Article history:}

Received $1^{\text {st }}$ February 2020

Received in revised form 17 May 2020

Accepted 20 August 2020

Available online 28 August 2020

\begin{abstract}
A B S T R A C T
Purpose. - Anti Programmed Death-ligand (PD1/PD-L1) directed immune-checkpoint-inhibitors (ICI) are widely used to treat patients with advanced non-small cell lung cancer (NSCLC) who progress after first line chemotherapy. The best strategy after early progression under first line has not been specifically studied.

Patients and methods. - We conducted a multicenter, retrospective study including all consecutive NSCLC patients progressing within the first 3 months following introduction of first-line chemotherapy and being treated with second line ICI monotherapy or chemotherapy between March 2010 and November 2017. We analysed the clinicopathological data and outcome under second line chemotherapy vs. second line ICI: objective response rate (ORR), progression-free survival (PFS), overall survival (OS.

Results. - We identified 176 patients with refractory disease, 99 who received subsequent immunotherapy and 77 undergoing chemotherapy. The 2 populations were comparable regarding the main prognostic criteria, median age was 60 , main histology was adenocarcimoma (68.2\%). PFS was not significantly different between both treatments 1.9 [1.8-2.1] versus 1.6 month [1.4-2.0] $(P=0.125)$. Compared to chemotherapy, ICI treated patients had a superior OS $(P=0.03)$ (Median [95\% CI] OS 4.6 [2.8-6.7] versus 4.2 months [3.4-5.9] and a non-significant improvement in ORR (17.2\% versus $7.9 \%$, respectively, $P=0.072$ ). Poor performance status (ECOG PS $\geq 2$ ) and a higher number of metastatic sites ( $\geq 3$ ) were associated with poorer prognosis. KRAS-mutated patients did not seem to benefit more from ICI than chemotherapy. Conclusions. - ICI appears to be the preferred second-line treatment for patients who are refractory to first line chemotherapy.
\end{abstract}

\section{Introduction}

Non-small cell lung cancer (NSCLC) treatment has been transformed over the last decade with the development of immune checkpoint inhibitors (ICI). The first studies were conducted in second line treatment and pembrolizumab, nivolumab (both programmed death-1 (PD-1) inhibitors [1-4], and atezolizumab (PD-L1 inhibitor), are currently registered for second line treatment [5]. Pembrolizumab monotherapy is registered in first line for those with a PD-L1 tumor proportion score of $\geq 50 \%$, and has recently been approved in combination with platinum-based chemotherapy

\footnotetext{
* Corresponding author at: Thoracic Oncology Department, Hopital Larrey, CHU Toulouse, Chemin de Pouvourville, 31059 Toulouse, France.

E-mail address: mazieres.j@chu-toulouse.fr (J. Mazières).
}

regardless of PD-L1 for non-squamous NSCLC [6]. Until recently, the only available first line strategy for advanced NSCLC patients without a targetable driver, and with a PD-L1 below 50\%, was a platinum doublet based chemotherapy.

However, only $20-40 \%$ of patients have an objective response on first line platinum-doublet chemotherapy and 20-30\% have refractory disease (defined as the progression occurring within the first 3 months from the beginning of the treatment) $[7,8]$. The standard of care in second line, for patients with good performance status (PS) and no contra-indication is progressively switching from taxanes to ICI. The ICI registered are nivolumab and atezolizumab regardless of PD-L1 status or pembrolizumab for PD-L1 positive patients. Objective response rate (ORR) to 2 nd line $\mathrm{ICI}$ is generally below $20 \%$, and only a minority of patients obtains long-term benefits [1-3]. Furthermore, $40 \%$ of patients treated with ICI have progressive disease (PD) as best response. Champiat et al. and later Ferrara et al. $[9,10]$ 
also described a hyperprogressive disease pattern on PD1/PD-L1 therapy with fast growing disease and poor prognosis. In these last studies, they found negative correlation on survival with age for the first one and with the number of metastatic locations for the second one.

Some predictive factors for ICI response were proposed and validated. PD-L1 expression on tumor cells was the first one to be addressed in clinical trials. LIPI (Lung Immune Pronostic Index) score based on Derived neutrophils ratio and LDH, was recently associated with overall survival (OS) in patients treated with ICI as a prognosis factor [11]. Unfortunately, these scores have a low sensitivity and specificity and are not statistically correlated with each other [12].

Patients with an aggressive disease, non-responding to firstline platinum-based chemotherapy, have a poor prognosis. It has been reported that, if time since initiation of the latest treatment is inferior to 6 months, patients have a poor prognosis on ICI with a median OS of 4.6 months [13]. Furthermore, it has been shown that response to chemotherapy immediately before nivolumab, particularly when combined with bevacizumab, increases the likelihood of disease control under nivolumab [14].

It is unclear to date whether patients with aggressive disease (progression within 3 months of start of first line treatment) can obtain a better survival with chemotherapy or ICI.

Therefore, we analysed data from advanced NSCLC patients with progression within the first three months of first line chemotherapy initiation and who received ICI or chemotherapy as second line treatment.

\section{Patients and Methods}

\subsection{Patient selection}

We conducted a retrospective, multicentric study. We included all consecutive patients with advanced or metastatic NSCLC who had PD according to RECIST 1.1 criteria within the first 3 months following first line platinum-based chemotherapy initiation and who subsequently received either 2 nd line monotherapy ICI (nivolumab, pembrolizumab or atezolizumab) or 2nd line chemotherapy (docetaxel, paclitaxel, pemetrexed, gemcitabine). The study was conducted in 4 centers: Institut Gustave Roussy (Villejuif, France), University Hospital of Toulouse and Bordeaux (France) and Maastricht University Medical Centre (MUMC, the Netherlands). Patients with a targetable molecular alteration (Anaplastic lymphoma kinase, ROS1, and Epidermal Growth Factor Receptor) were excluded.

\subsection{Data Collection and response assessment}

We extracted data from the medical records, including: age and Eastern Cooperative Oncology Group Performance Status (ECOG PS) at the beginning of first line chemotherapy and before the start of second line therapy, gender, smoking history, histology, molecular profiling, details of first and second line therapy including start and end date, best response according to RECIST 1.1, and date of death or last follow-up).

We included patients who had begun first line treatment between March 2010 and November 2017 (Chemotherapy: March 2010-May 2017; ICI: May 2014-November 2017). Finally, we collected post second line treatment when it was done.

\subsection{Study objectives and outcomes}

Each center locally assessed response to systemic therapies using RECIST v1.1 criteria, defined as a complete or partial response (CR/PR), stable disease (SD) or PD during therapy. We collected data of progression; Progression Free Survival (PFS) and Overall Survival, date of death (or last follow-up) and patients' characteristics. ORR was defined as CR or PR.

We divided the PFS on both 2nd line treatments into 3 groups: Progression within the first 2 months corresponding approximately to hyperprogressive disease description, progression between 2 and 6 months and progression after 6 months. The 2 months cutoff for PFS was used corresponding to the first evaluation in daily practice of the three major ICI drugs. 6 months being approximately the time we observed long responders PFS curve stabilisation on ICI landmark study.

The primary objective was to compare progression free survival of NSCLC patients who are refractory to first line chemotherapy and who were subsequently treated with immunotherapy single agent versus second line chemotherapy. Secondary objectives were ORR, OS, and identification of potential predictive clinical or biological factors.

\subsection{Statistical methods}

Demographic and clinical data were presented according to treatment modality (chemotherapy vs. ICI). Qualitative variables were summarized using counts, percent, number of missing data. Comparisons between groups were performed through chi-square or Fisher's exact test.

Association between variables and early progression ( $<2$ months) on ICI treatment were quantified by the Odds Ratio (ORs) and their corresponding confidence intervals (CIs) in univariable and multivariable analysis using logistic regression models.

All survival times were calculated from the initiation of second line treatment and estimated by the Kaplan-Meier method with 95\% confidence intervals ( $\mathrm{CI}$ ), using the following first event definitions: progression or death from any cause for PFS and death from any cause for OS. Patients still alive without event of interest were censored at last follow-up. Time-to-event end points were analysed by using the log rank test for univariable analysis and Cox proportional hazards regression model for multivariable analysis Hazard Ratios (HR) were estimated with 95\% confidence intervals.

All statistical tests were two-sided and p-values $<0.05$ were considered significant. Statistical analyses were conducted using Stata ${ }^{\circledR}$, version 13.

\section{Result}

\subsection{Patient characteristics}

We identified 176 patients who fulfilled the eligibility criteria: 99 received second line immunotherapy and 77 second line chemotherapy. The main characteristics of these two cohorts are reported in Table 1. Both populations were comparable regarding age (60yrs in the ICI group vs. $59 \mathrm{yrs}$ in the chemo group), smoking habits ( $97 \%$ of smokers in both groups), and histological subtypes (adenocarcinoma for 65\% and 73\%) and molecular subtypes (KRAS mutation). The number of patients with more than 2 metastatic sites at diagnosis was higher in the ICI group (32.3\% versus $15.6 \% P=0.01$ ). Metastatic sites at diagnosis and before second line were not different between both groups except for adrenals and nodal metastasis (respectively $30.3 \%$ and $28.3 \%$ in ICI group, $9.1 \%$ $(P<0.001)$ and $10.3 \%(P=0.003)$ in the chemotherapy group). ECOG PS was significantly better in the ICI group, $27.6 \%$ of patients having a PS score of $\geq 2$ versus $44.2 \%$ in the chemotherapy group $(P=0.022)$. Additionally, LIPI score was available for 62 patients (35.2.\%), the percentage of patients with a poor LIPI score (i.e. score 1 or 2 ) was 
Table 1

Patients characteristics and association between 2nd line therapy status and clinical categorical variables (univariable analysis).

\begin{tabular}{|c|c|c|c|c|}
\hline \multicolumn{5}{|l|}{ 2nd Line treatment } \\
\hline & Total & ICI 2nd line & CT 2nd line & \\
\hline & $n=176$ & $n=99$ & $n=77$ & \\
\hline Age (years) & & & & 0.095 \\
\hline$\geq 60$ & $88(50.0 \%)$ & $44(44.4 \%)$ & $44(57.1 \%)$ & \\
\hline$<60$ & $88(50.0 \%)$ & $55(55.6 \%)$ & $33(42.9 \%)$ & \\
\hline Smoking history & & & & 0.298 \\
\hline Current/Former & 169 (97.1\%) & 95 (96.9\%) & $74(97.4 \%)$ & \\
\hline Non-smoker & $5(2.9 \%)$ & $3(3.1 \%)$ & $2(2.6 \%)$ & \\
\hline Missing & 2 & 1 & 1 & \\
\hline Histology & & & & 0.146 \\
\hline Adenocarcinoma & $120(68.2 \%)$ & $64(64.6 \%)$ & $56(72.7 \%)$ & \\
\hline NSCLC-other & $15(8.5 \%)$ & $12(12.1 \%)$ & $3(3.9 \%)$ & \\
\hline Squamous & $41(23.3 \%)$ & $23(23.2 \%)$ & $18(23.4 \%)$ & \\
\hline \multicolumn{5}{|l|}{ PD-L1 status } \\
\hline PD-L1 negative & $11(28.2 \%)$ & $8(22.9 \%)$ & $3(75 \%)$ & \\
\hline PD-L1 positive & $28(71.8 \%)$ & $27(77.1 \%)$ & $1(25 \%)$ & \\
\hline Missing & 137 & 64 & 73 & \\
\hline Stage at diagnosis & & & & 0.117 \\
\hline III & $18(10.2 \%)$ & $7(7.1 \%)$ & $11(14.3 \%)$ & \\
\hline IV & $158(89.8 \%)$ & $92(92.9 \%)$ & $66(85.7 \%)$ & \\
\hline KRAS mutation & & & & 0.923 \\
\hline Yes & $52(45.6 \%)$ & $34(45.9 \%)$ & $18(45.0 \%)$ & \\
\hline No & $62(54.4 \%)$ & $40(54.1 \%)$ & $22(55.0 \%)$ & \\
\hline Missing & 59 & 25 & 37 & \\
\hline $\mathrm{N}^{\circ}$ metastatic sites before 2 nd line & & & & $<0.001$ \\
\hline$\leq 3$ & $93(52.8 \%)$ & $40(40.4 \%)$ & $53(68.8 \%)$ & \\
\hline$>3$ & $83(47.2 \%)$ & $59(59.6 \%)$ & $24(31.2 \%)$ & \\
\hline Performance Status before 2nd line & & & & 0.022 \\
\hline $0-1$ & $114(65.1 \%)$ & $71(72.4 \%)$ & $43(55.8 \%)$ & \\
\hline$\geq 2$ & $61(34.9 \%)$ & $27(27.6 \%)$ & $34(44.2 \%)$ & \\
\hline Missing & 1 & 1 & 0 & \\
\hline $\mathrm{dNLR}>3$ before 2 nd line & & & & 0.126 \\
\hline No & $71(55.5 \%)$ & $48(60.8 \%)$ & $23(46.9 \%)$ & \\
\hline Yes & $57(44.5 \%)$ & $31(39.2 \%)$ & $26(53.1 \%)$ & \\
\hline Missing & 48 & 20 & 28 & \\
\hline
\end{tabular}

higher in the chemotherapy group (Chemo: $93.8 \%$ vs. ICI: $63.0 \%$, $P=0.025$ ).

\subsection{Patient outcome}

Median PFS [95\% CI] for the chemotherapy versus the ICI subgroup was [1.9 $(1.8-2.1)$ versus 1.6 months $(1.4-2.0)](P=0.125)$ (Fig. 1). We divided PFS on 2nd line treatment into 3 groups: Progression within the first 2 months, progression between 2 and 6 months and progression after 6 months. The population's distribution in the various previously defined PFS groups is shown in Table 2. There were significantly more patients who did not progress at 6 months in the ICI group ( $22.3 \%$ vs. $10.4 \%, P=0.006)$.

Overall survival was better in ICI group than in chemotherapy group $(P=0.031)$ with a median OS of 4.6 months [95\%CI: 2.8 ; 6.7] versus 4.2 months [95\%CI: 3.4; 5.9] (Fig. 2). Noteworthy, immunotherapy OS curve goes below than chimiotherapy's curve in the first three months in this figure.

The ORR was numerically increased in patients treated with ICI compared to chemotherapy: $17.2 \%$ vs. $7.9 \%(P=0.072)$. These results are non significant.

\subsection{Subgroup analysis}

Factors associated with both poor PFS and poor OS in univariable analysis for both populations were ECOG PS $\geq 2(P=0.027$ and $P=0.001$, respectively), more than 2 metastatic sites $(p=0.022$ and $P=0.002)$ and liver metastases $(P=0.027$ and $P=0.014)$ (Table 3$)$. High LIPI score ( 1 or 2$)$ was also associated with a poor OS $(P=0.016)$. In Cox multivariable analysis after backward selection,
ICI [HR $0.71(0.51-0.98), P=0.040]$ and $\geq 3$ metastatic sites [1.52 (1.10-2.10), $P=0.011$ ] were both related to PFS (Table 4).

We considered, then, the factors associated with rapid progression on ICI treatment ( $<2$ months). In univariable analysis, Performance Status before 2nd line [Odds Ratio OR 3.40 [1.23; 9.43] $P=0.019$ ], more than 2 metastatic sites (OR 2.57 [1.12; 5.89] $P=0.025)$ and hepatic metastasis [OR $4.40[1.50 ; 12.90] P=0.007]$ were associated with a rapid progression. Multivariable model confirmed these results for hepatic metastasis [OR $5.10(1.68 ; 15.45)$ $P=0.004$ ] and Performance Status $\geq 2$ [OR 3.90 (1.35; 11.28), $P=0.012$ ] (Table 5)

We compared ICI and chemotherapy PFS and OS results for the 2 main histologic subtypes and for KRAS status. We did not find any difference between treatments in OS $(P=0.27)$ and PFS $(P=0.16)$ for both major histologic subtypes of NSCLC (squamous and adenocarcinoma). Patients bearing KRAS mutation $(n=52 ; 18$ in chemotherapy subgroup, 34 in ICI subgroup) had a median PFS of 1.9 month [1.8;3.4] in the chemotherapy group and 1.4 month $[1.1 ; 2.0]$ in the ICI group $(P=0.509)$. For KRAS wild-type patients ( $N=62 ; 22$ in chemotherapy subgroup, 40 in ICI subgroup), even though PFS of ICI [median PFS 1.7 month $(1.1 ; 7.4)$ ] and chemotherapy patients [ 1.9 months $(1.4 ; 4.1)](P=0.129)$ were similar, OS in ICI treated patients was significantly better than in the chemotherapy group [median OS 6.0 (3.2; NR) $P=0.033$ ] (Fig. 3).

In ICI treated patients, those with positive PD-L1 status $(\geq 1 \%)$ $(n=27)$ was associated with a better PFS $(P=0.009)$ (median PFS 3.7 [1.1-not reached] versus 0.7 months $[0.4-1.6](P=0.009)(n=8)$.

\subsection{Third line treatment}

In the ICI group, $18(18.2 \%)$ patients were still under treatment. 58 (58.6\%) did not receive further treatment and 23 (23.2\%) patients 


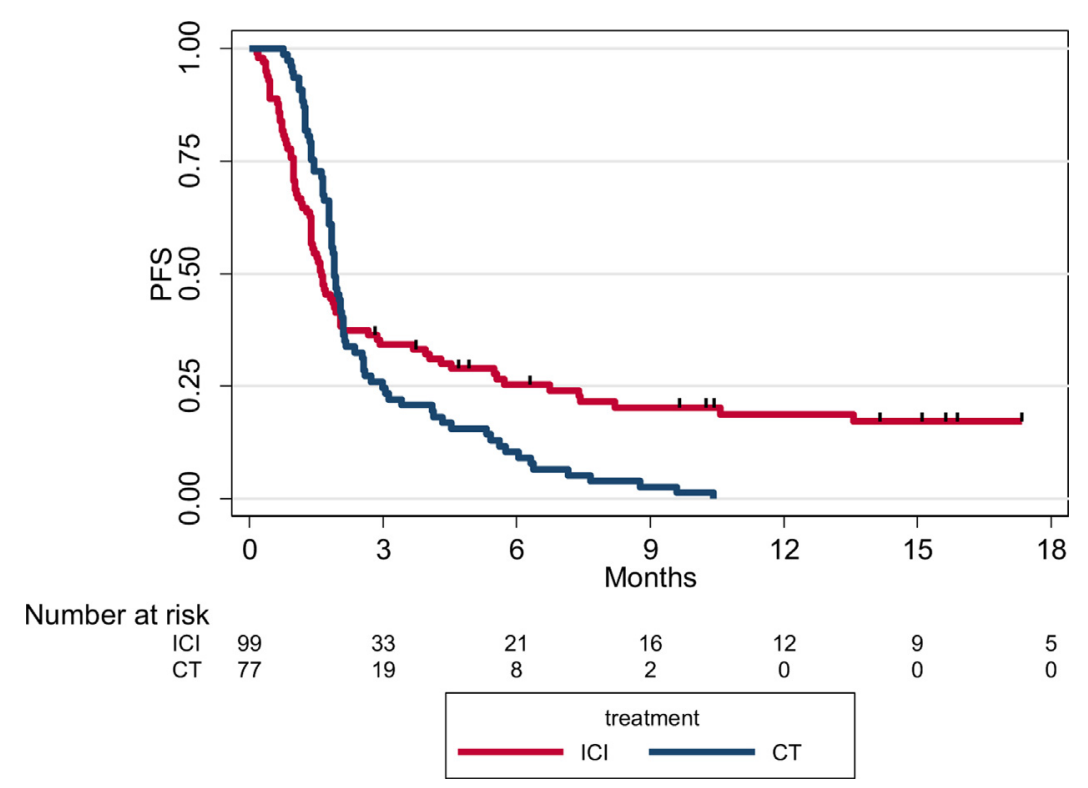

Fig. 1. Kaplan Meier curves for Progression Free survival for both ICI group and CT group.

Table 2

PFS sub-class analyses.

\begin{tabular}{llll}
\hline 2nd Line treatment & & & \\
\hline & Total & ICl 2nd line & CT 2nd line \\
\cline { 2 - 4 } & $n=176$ & $n=99$ & $n=77$ \\
\hline PFS subdivised (3cl) $(n=171)$ & & & $42(54.5 \%)$ \\
$\quad<2$ months PD & $100(58.5 \%)$ & $58(61.7 \%)$ & $27(35.1 \%)$ \\
2-6 month PD & $42(24.6 \%)$ & $15(16.0 \%)$ & $8(10.4 \%)$ \\
No PD at 6 months & $29(17.0 \%)$ & $21(22.3 \%)$ & 0.006 \\
Missing & 5 & 5 & 0 \\
\hline
\end{tabular}
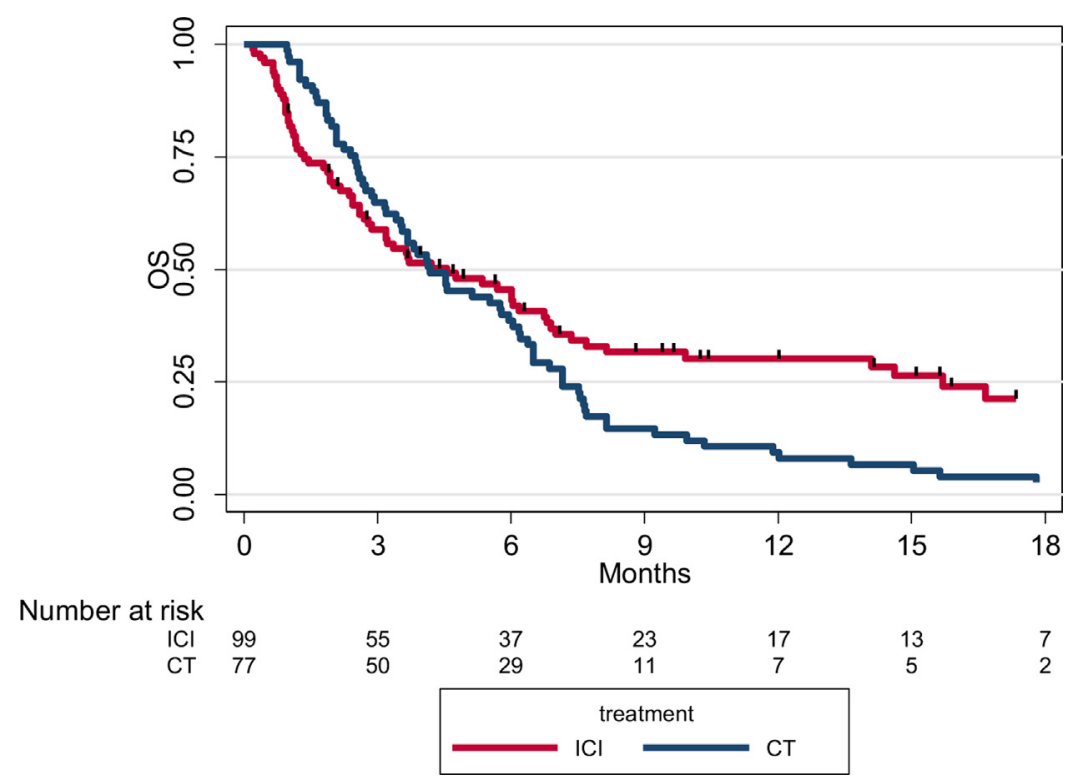

Fig. 2. Kaplan Meier curves for Overall Survival for both ICI group and CT group.

received third line treatment (chemotherapy for 21 patients and tyrosine Kinase inhibitors for 2 of them).

In the chemotherapy group, 53 patients $(68.8 \%)$ didn't receive third line treatment, 24 (31.2\%) received third line treatment (10 chemotherapies, 6 nivolumab and 3 Tyrosine Kinase inhibitors).

\section{Discussion}

Advanced NSCLC patients who are refractory to first line chemotherapy are frequent in our daily practice. The prognosis of these patients remains poor, therapeutic options are often limited and the best treatment strategy remains uncertain. No 
Table 3

Univariable analysis of characteristics associated with OS and PFS.

\begin{tabular}{|c|c|c|c|c|}
\hline \multirow[b]{2}{*}{ Variable } & \multicolumn{2}{|l|}{ OS } & \multicolumn{2}{|l|}{ PFS } \\
\hline & Median (months) [CI 95\%] & $P$-value & Median (months) [CI 95\%] & $P$-value \\
\hline Treatment & & 0.0305 & & 0.1248 \\
\hline Chemotherapy & $4.2[3.4 ; 5.9]$ & & $1.9[1.8 ; 2.1]$ & \\
\hline Immunotherapy & $4.6[2.8 ; 6.7]$ & & $1.6[1.4 ; 2.0]$ & \\
\hline Number of metastatic location before 2nd line & & 0.0017 & & 0.0222 \\
\hline $0-1-2$ (ref) & $6.4[4.5 ; 7.2]$ & & $2.0[1.8 ; 2.6]$ & \\
\hline 3 or + & $2.6[2.0 ; 3.6]$ & & $1.5[1.2 ; 1.9]$ & \\
\hline Performance Status & & 0.0010 & & 0.0273 \\
\hline $0-1$ & $6.0[3.8 ; 6.9]$ & & $2.0[1.8 ; 2.5]$ & \\
\hline $2-3-4$ & $2.5[1.9 ; 4.2]$ & & $1.4[1.2 ; 1.9]$ & \\
\hline Hepatic metastases & & 0.0143 & & 0.0275 \\
\hline No & $4.8[3.7 ; .2]$ & & $1.9[1.8 ; 2.1]$ & \\
\hline Yes & $2.9[1.8 ; .0]$ & & $1.4[1.2 ; 1.8]$ & \\
\hline LIPI Score & & 0.0158 & & 0.1985 \\
\hline 0 & $18.7[2.6 ; \mathrm{NR}]$ & & $2.6[1.4 ; 7.4]$ & \\
\hline $1-2$ & $3.7[1.9 ; 5.9]$ & & $1.8[1.3 ; 2.9]$ & \\
\hline
\end{tabular}

Table 4

Final multivariable analysis of characteristics associated with OS and PFS (after backward selection method).

\begin{tabular}{|c|c|c|c|c|}
\hline \multirow{2}{*}{$\begin{array}{l}n=175 \\
\text { Variable }\end{array}$} & \multicolumn{2}{|l|}{ OS } & \multicolumn{2}{|l|}{ PFS } \\
\hline & HR [CI 95\%] & $P$-value & HR [CI 95\%] & $P$-value \\
\hline Treatment & & 0.045 & & 0.040 \\
\hline Chemotherapy (ref) & 1.00 & & 1.00 & \\
\hline Immunotherapy & $0.70[0.49 ; 0.99]$ & & $0.71[0.51 ; 0.98]$ & \\
\hline Number of metastatic location before 2 nd line & & 0.005 & & 0.011 \\
\hline $0-1-2($ ref $)$ & 1.00 & & 1.00 & \\
\hline 3 or + & $1.64[1.16 ; 2.31]$ & & $1.52[1.10 ; 2.10]$ & \\
\hline Performance Status & & 0.038 & & \\
\hline $0-1$ (ref) & 1.00 & & & \\
\hline $2-3-4$ & $1.46[1.02 ; 2.09]$ & & & \\
\hline
\end{tabular}

Table 5

Characteristics associated with fast progression ( $<2$ months) on ICI.

\begin{tabular}{|c|c|c|}
\hline \multirow{2}{*}{$\begin{array}{l}\mathrm{n}=98 \\
\text { Variable }\end{array}$} & \multicolumn{2}{|c|}{ Final model (after backward selection method) } \\
\hline & OR [CI 95\%] & $P$-value \\
\hline \multicolumn{3}{|c|}{ Performance Status } \\
\hline $0-1$ (ref) & 1.00 & \\
\hline $2-3-4$ & $3.90[1.35 ; 11.28]$ & 0.012 \\
\hline \multicolumn{3}{|c|}{ Hepatic metastasis } \\
\hline No (ref) & 1.00 & \\
\hline Yes & $5.10[1.68 ; 15.45]$ & 0.004 \\
\hline
\end{tabular}

studies specifically studied response to chemotherapy versus ICI in this setting. Although landmark studies have collected data regarding previous treatment response, they have not looked on best treatment approach for refractory disease patients [1-3,5] Some retrospective studies described a lower ORR with ICI in chemorefractory patients, but these studies did not address the best treatment strategy (i.e. ICI or chemotherapy 2nd line) in first line chemotherapy refractory patients [13-16].

Our multicenter, retrospective study evaluated the outcome of second line ICI and chemotherapy treatment in this specific patient population; OS was significantly improved with ICI compared with chemotherapy but non clinically relevant as it improves OS of 0,4 months. Although ORR (17.2\%) on ICI was comparable to landmark trials $[1-3,5]$, the prognosis patients who are refractory to first line chemotherapy remains poor with a mortality rate of $80 \%$ within the first year. In contrast with the landmark trials, median PFS and OS were low in our series for both chemotherapy and ICI (PFS: 1.8 and OS 4.2 months, respectively), compared with a median PFS of 4.2 (docetaxel) and 2.3 months (nivolumab), and a median OS of 9.4 (docetaxel) and 12.2 months (nivolumab) in the CheckMate 057 trial $[1,2,4,5]$.
Treating patients who do not respond to first line chemotherapy has always been challenging [17]. In this context, results with 2nd line chemotherapy have been disappointing. Therefore, it is of interest to assess ICI efficacy in this patient population. We found that, although OS with 2nd line ICI is superior to OS with 2nd line chemotherapy, outcome remains poor. Mechanism that could explain this result is that the immune system might be overloaded by tumor aggressiveness in these immunocompromised patients. As an example, patients have frequently a poor performance status ( $P S \geq 2$ for $34.9 \%$ of patients) at the time of second line beginning due to aggressive disease with organ dysfunction and comorbidities.

It has been shown for patients progressing rapidly under first line chemotherapy that the combination of docetaxel and one of the VEGF (Vascular Endothelial Growth Factor) inhibitors nintedanib or ramucirumab was more effective than docetaxel alone, especially for first line refractory patients and in the adenocarcinoma subgroup $[18,19]$. In Lume-Lung 1, patients with adenocarcinoma and time since start of first line therapy (TSFLT) $<9$ months, median PFS was 3.6 months for docetaxel and nintedanib association versus 1.5 months for chemotherapy alone in second line for pretreated patients. This median PFS of 1.5 months for second line docetaxel without nintedanib is closed from our results (1.6 months for second line chemotherapy arm). Interestingly our median OS result for this population is shorter in our study in chemotherapy arm (4.2 months) than LUME (7.9 months in chemotherapy alone arm). Two main reasons may explain this OS difference. First of all our patients had PS $\geq 2$ for $34 \%$ of them on contrary of LUME-lung 1 in which only PSO-1 patients were enrolled. Second of all, we had a shorter cut-off to define refractory disease ( 9 months versus 3 months). Nevertheless, considering PFS and OS differences between 2nd line ICI on our study (respectively 1.9 months and 4.6 months) and 2nd line nintedanib and docetaxel in Lume-lung 1 (respectively 3.6 months 


\section{A Mutation KRAS}
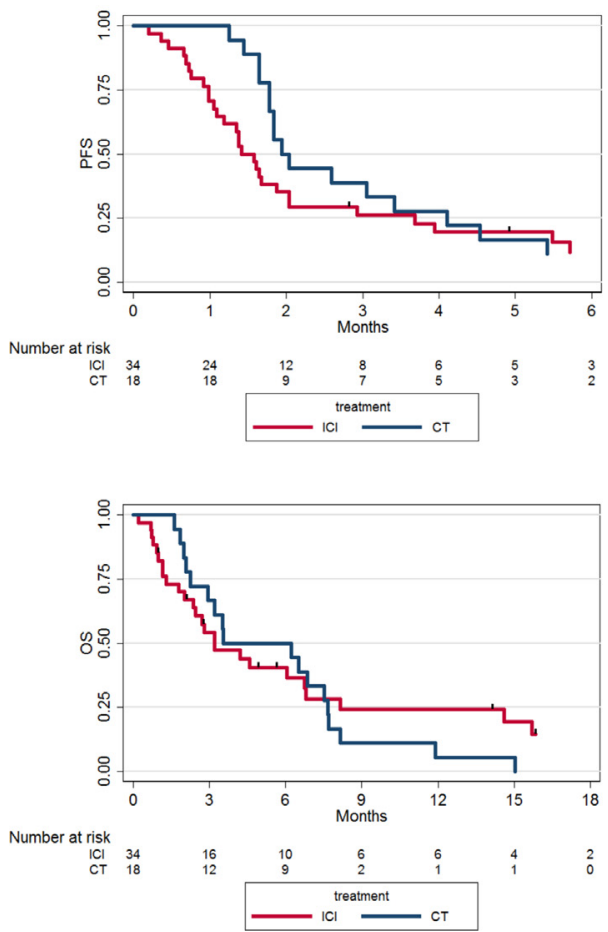

\section{B KRAS Wild Type}
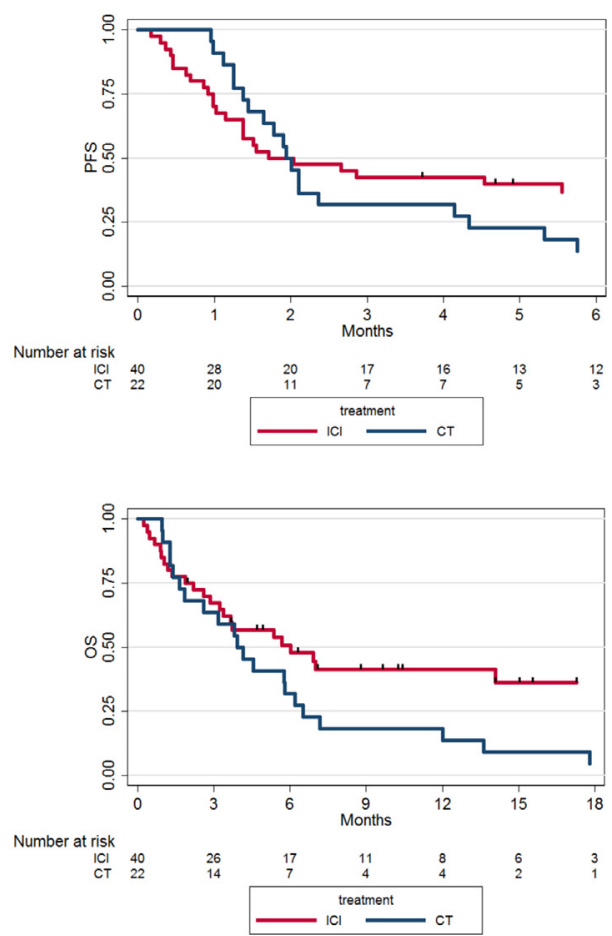

Fig. 3. Effect of treatment on KRAS mutated patients and KRAS Wild Type. PFS (2A) and OS (2B).

and 10.2 months), we might consider VEGF inhibitors in second line as an option for platinum refractory patients.

Factors related to unfavorable prognosis in our study were poor PS, 3 or more metastatic sites and especially the presence of liver metastases as already shown by Tamiya et al. [20], and Riihimäki et al.[21]. This poor prognosis on ICI after first line progression was previously reported by Garde Noguera et al. with a median OS of 4.6 months for patients progressing within the six first months of platinum-doublet first line chemotherapy [13]. The LIPI, developed by Mezquita et al. for outcome on ICI, could not be precisely studied due to missing LIPI for $64.8 \%$ of patients. Nevertheless, we found that a high LIPI is a poor prognostic factor on OS for our patients with a median OS of 3.7 months for LIPI score of 1 or 2 vs. 18.7 months for LIPI 0 in the whole population. Another feature raised by our study is a possible hyperprogressive disease patterns with a PFS cuve in disfavour of ICI in the two first months. It appears that patients with a large number of metastatic sites $(\geq 3)$ and an altered general state (PS $\geq 2$ ) are predisposed to progress within the first two months. If one of these 2 prognosis factors is present, the probability of a rapid progression is $78 \%$ versus $39.2 \%$ if none of them is present. Considering that registration, following the landmark studies, need a PS of $0-1$ for ICI prescription, we may stay cautious on ICI prescription for $\mathrm{PS} \geq 2$ patients.

This data are consistent with conclusions of Ferrara et al. [9]. Our study failed to formally identify patients who may benefit more from chemotherapy than immunotherapy.

Our study has some limitations. First, it is a retrospective study with inherent selection bias and missing data, although both groups were well balanced for main clinical and biological characteristics. Most of the patients treated with chemotherapy were treated before 2015 and patients with ICI after 2015 (immunotherapy approval). Therefore, some patients undergoing second line chemotherapy did not benefit from third line ICI as it was not available at that time although some ICI patients could potentially benefit from third line docetaxel after progression. Moreover,
Schvartsmann et al. [22] suggested that chemotherapy after ICI is more effective, contributing to OS improvement in ICI patients.

Noteworthy, first line therapy strategy is currently changing with the recent approval of platinum doublet and pembrolizumab combination [6]. These results let us think that the additive effect of ICI to CT will still be seen in patient refractory to chemo. Nevertheless in this last study, $22 \%$ of patients had a progressive disease at 3 months. The next challenge will thus be to determine the best strategy in patients who are refractory to the combination.

Despite its retrospective nature, this study helps to clarify the best strategy to set up in patients who are refractory to first line chemotherapy. Second line immunotherapy seems to be associated with a more durable benefit in this poor prognosis population.

\section{Disclosure of interest}

The authors declare that they have no competing interest.

\section{References}

[1] Borghaei H, Paz-Ares L, Horn L, et al. Nivolumab versus docetaxel in advanced nonsquamous non-small-cell lung cancer. N Engl J Med 2015;373:1627-39.

[2] Brahmer J, Reckamp KL, Baas P, et al. Nivolumab versus docetaxel in advanced squamous-cell non-small-cell lung cancer. N Engl J Med 2015;373:123-35.

[3] Herbst RS, Baas P, Kim D-W, et al. Pembrolizumab versus docetaxel for previously treated, PD-L1-positive, advanced non-small-cell lung cancer (KEYNOTE-010): a randomised controlled trial. Lancet Lond Engl 2016;387:1540-50.

[4] Reck M, Rodríguez-Abreu D, Robinson AG, et al. Pembrolizumab versus chemotherapy for PD-L1-Positive non-small-cell lung cancer. N Engl J Med 2016;375:1823-33.

[5] Rittmeyer A, Barlesi F, Waterkamp D, et al. Atezolizumab versus docetaxel in patients with previously treated non-small-cell lung cancer (OAK): a phase 3, open-label, multicentre randomised controlled trial. Lancet Lond Engl 2017;389:255-65

[6] Gandhi L, Rodríguez-Abreu D, Gadgeel S, et al. Pembrolizumab plus chemotherapy in metastatic non-small-cell lung cancer. N Engl J Med 2018;378:2078-92.

[7] Patel JD, Socinski MA, Garon EB, et al. PointBreak: a randomized phase III study of pemetrexed plus carboplatin and bevacizumab followed by maintenance pemetrexed and bevacizumab versus paclitaxel plus carboplatin and beva- 
cizumab followed by maintenance bevacizumab in patients with stage IIIB or IV nonsquamous non-small-cell lung cancer. J Clin Oncol Off J Am Soc Clin Oncol 2013;31:4349-57.

[8] A. Sandler, R. Gray, M.C. Perry, J. Brahmer, J.H. Schiller, A. Dowlati, et al. Paclitaxel-carboplatin alone or with bevacizumab for non-small-cell lung cancer. - PubMed - NCBI. https://www-ncbi-nlm-nihgov.gate2.inist.fr/pubmed/17167137.(accessed Feb 19, 2018).

[9] Ferrara R, Mezquita L, Texier $M$, et al. Hyperprogressive disease in patients with advanced non-small cell lung cancer treated with PD-1/PD-L1 inhibitors or with single-agent chemotherapy. JAMA Oncol 2018;4:1543-52, http://dx.doi.org/10.1001/jamaoncol.2018.3676, published online Sept 6 .

[10] Champiat S, Dercle L, Ammari S, et al. Hyperprogressive disease is a new pattern of progression in cancer patients treated by Anti-PD-1/PD-L1. Clin Cancer Res Off J Am Assoc Cancer Res 2017;23:1920-8.

[11] Mezquita L, Auclin E, Ferrara R, et al. Association of the lung immune prognostic index with immune checkpoint inhibitor outcomes in patients with advanced non-small cell lung cancer. JAMA Oncol 2018, http://dx.doi.org/10.1001/jamaoncol.2017.4771, published online Jan 11.

[12] Rizvi H, Sanchez-Vega F, La K, et al. Molecular determinants of response to anti-programmed cell death (pd)-1 and anti-programmed death-ligand (PDL)-Ligand 1 blockade in patients with non-small-cell lung cancer profiled with targeted next-generation sequencing. J Clin Oncol Off J Am Soc Clin Oncol 2018. JCO2017753384.

[13] Garde-Noguera J, Martorell PM, De Julián M, et al. Predictive and prognostic clinical and pathological factors of nivolumab efficacy in non-small-cell lung cancer patients. Clin Transl Oncol 2018, http://dx.doi.org/10.1007/s12094-017-1829-5, published online Jan 24.

[14] Nakahama K, Isa S-I, Tamiya A, et al. The association between chemotherapy immediately before nivolumab and outcomes thereafter. Anticancer Res 2017;37:5885-91.
[15] Kaderbhai C-G, Richard C, Fumet JD, et al. Response to first line chemotherapy regimen is associated with efficacy of nivolumab in non-small-cell lung cancer. Oncoimmunology 2017;6:e1339856.

[16] Inoue T, Tamiya M, Tamiya A, et al. Analysis of early death in japanese patients with advanced non-small-cell lung cancer treated with nivolumab. Clin Lung Cancer 2018;19:e171-6.

[17] Giroux Leprieur E, Antoine M, Vieira T, et al. Clinical and molecular features in patients with advanced non-small-cell lung carcinoma refractory to first-line platinum-based chemotherapy. Lung Cancer Amst Neth 2013;79:167-72.

[18] Garon EB, Ciuleanu T-E, Arrieta O, et al. Ramucirumab plus docetaxel versus placebo plus docetaxel for second-line treatment of stage IV non-small-cell lung cancer after disease progression on platinum-based therapy (REVEL): a multicentre, double-blind, randomised phase 3 trial. Lancet Lond Engl 2014;384:665-73.

[19] Reck M, Kaiser R, Mellemgaard A, et al. Docetaxel plus nintedanib versus docetaxel plus placebo in patients with previously treated non-small-cell lung cancer (LUME-Lung 1): a phase 3, double-blind, randomised controlled trial Lancet Oncol 2014;15:143-55.

[20] Tamiya M, Tamiya A, Inoue T, et al. Metastatic site as a predictor of nivolumab efficacy in patients with advanced non-small cell lung cancer: A retrospective multicenter trial. PLoS ONE 2018;13:e0192227.

[21] Riihimäki M, Hemminki A, Fallah M, et al. Metastatic sites and survival in lung cancer. Lung Cancer 2014;86:78-84.

[22] Schvartsman G, Peng SA, Bis G, et al. Response rates to singleagent chemotherapy after exposure to immune checkpoint inhibitors in advanced non-small cell lung cancer. Lung Cancer 2017, http://dx.doi.org/10.1016/j.lungcan.2017.07.034, published online Aug 3. 